\section{Peduncular Hallucinosis}

Jennifer Sue Kleiner

Department of Psychiatry, University of Arkansas for Medical Sciences, Little Rock, AR, USA

\section{Definition}

Peduncular hallucinosis is a relatively rare type of hallucination that can occur following the lesions of the occipital cortices, diencephalon (e.g., medial thalami or fornices), or upper portion of the brain stem (Tekin and Cummings 2003). One of the more common causes is infarctions at the distal portions of the basilar artery. Known as the "top-of-the-basilar syndrome," this disorder can result in a variety of symptoms including ocular disturbances, ataxia, altered sleep, agitation, confusion and memory deficits, as well as peduncular hallucinations. These hallucinations are frequently characterized by vividly colored landscapes, animals, or people, which are often seen to be in motion. They frequently, but not invariably, occur under low-light conditions, and the patient may have difficulty differentiating them from true, eternally based visual phenomena.

\section{Cross-References}

- Hallucination

\section{References and Readings}

Benke, T. (2006). Peduncular hallucinosis - a syndrome of impaired reality monitoring. Journal of Neurology, 253 (12), 1561-1571.

Cummings, J. L., \& Miller, B. (1987). Visual hallucinations. Clinical occurrence and use in differential diagnosis. The Western Journal of Medicine, 146, 46-51.

Mocellin, R., Walterfang, M., \& Velakoulis, D. (2006). Neuropsychiatry of complex visual hallucinations. The Australian and New Zealand Journal of Psychiatry, 40(9), 742-751.

Tekin, S., \& Cummings, J. L. (2003). Hallucinations and related conditions. In K. M. Heilman \& E. Valenstein (Eds.), Clinical neuropsychology (4th ed., pp. 479-494). New York: Oxford University Press. 